\title{
3D Printing Pharmaceuticals: Drug Development to
}

\section{Front-line Care}

Sarah J. Trenfield ${ }^{1}$, Atheer Awad ${ }^{1}$, Alvaro Goyanes ${ }^{2}$, Simon Gaisford ${ }^{1,2}$ and Abdul W. Basit ${ }^{1,2^{*}}$

${ }^{1}$ UCL School of Pharmacy, University College London, 29-39 Brunswick Square, London, WC1N 1AX, UK

${ }^{2}$ FabRx Ltd., 3 Romney Road, Ashford, Kent, TN24 0RW, UK

*Correspondence: a.basit@ucl.ac.uk (Abdul W. Basit)

\section{Key words}

Three-dimensional printing; first-in-human; clinical trials; additive manufacturing; personalised medicines; drug development 


\begin{abstract}
$3 \mathrm{D}$ printing is forecast to be a highly disruptive technology within the pharmaceutical sector. In particular, the main benefits of 3D printing lie in the production of small batches of medicines each with a tailored dosage, shape, size and release characteristics. Manufacture of medicines this way may finally lead to the concept of personalised medicines becoming reality. In the shorter term, 3D printing could be extended throughout the drug development process, ranging from pre-clinical development and clinical trials, through to front-line medical care. This review aims to provide a timely perspective on the motivations and potential applications of 3D printing pharmaceuticals, as well as a practical viewpoint on how 3D printing could be integrated across the pharmaceutical space.
\end{abstract}

\title{
1.0. The Power of 3D Printing Pharmaceuticals
}

We are living in a technological era; we stand on the brink of the next industrial revolution, where living in a world of cloud-based computing, contactless payments and three-dimensional printing (3DP), which were once fantasy, have now become reality. The pharmaceutical industry is conservative, preferring established manufacturing processes and formulation design to ensure product stability, but by understanding and embracing the power of innovative technologies to support manufacturing processes the industry could revolutionise the way medicines are designed for individual patients. 
By depositing material layer-by-layer, 3DP can fabricate objects of virtually any shape and size on demand. Structures are created from a digital 3D file obtained using computer-aided design (CAD) software enabling bespoke and individualised objects to be readily manufactured. As such, 3DP has found applications in many industries, ranging from rapid prototyping in engineering to personalised devices in medicine $[1,2]$.

More recently, the technology has been applied to pharmaceuticals to manufacture medical devices [3-5] and 'printlets', which is a word that we have coined to refer to 3D printed solid oral dosage forms. Thus far, a wide range of formulations has been produced, including those containing multiple active pharmaceutical ingredients (APIs) [6-8], with different geometries [9] and release characteristics $[10,11]$. Favourably, the technology enables precise dosages to be deposited based on the initial 'ink' concentration and the physical dimensions of the formulation. Furthermore, in 2016, the first 3D printed tablet approved by the Food and Drug Administration (FDA) was commercialised for the treatment of epilepsy $\left(\right.$ Spritam $^{\circledR}$ by Aprecia Pharmaceuticals, https://http://www.spritam.com/ _ $\quad$ /hcp/zipdosetechnology/manufactured-using-3d-printing).

The introduction of 3DP to pharmaceuticals has the potential to cause a paradigm shift in the way that medicines are designed, used and manufactured. Conventional pharmaceutical manufacturing processes were first introduced around 200 years ago and, despite the significant technological advancements in the $21^{\text {st }}$ century, many of these are still in use 
today. Whilst these methods are cost-effective for large-scale production, they can be inherently time consuming, labour intensive and, because of the large batch sizes needed, dose inflexible. Using 3DP could revolutionise the way that tablets are manufactured, moving away from a 'one size fits all approach' toward personalised medicines. Indeed, 3DP could be utilised throughout the drug development timeline, ranging from pre-clinical development and firstin-human (FIH) clinical trials through to front-line medical care.

It is more important than ever for the pharmaceutical industry not to resist change, but instead to understand and embrace the power of innovative technologies to support manufacturing processes. This review aims to discuss the motivations and applications of 3DP in pharmaceuticals, associated challenges to implementation and to provide a unique and timely perspective on how 3DP could be integrated in clinical practice.

\subsection{Motivations of 3D Printing Pharmaceuticals}

3DP has enormous potential to revolutionise the way medicines are produced by providing a simple and rapid means of producing customised small or 'oneoff' batches. Whilst seven main categories of 3DP technologies have been classified [12], within pharmaceuticals, five main 3DP technologies have been researched; binder jet printing, fused deposition modelling (FDM), semi-solid extrusion, selective laser sintering (SLS) and stereolithography (SLA). Examples of the types of formulations that have been produced using each technology are provided in Table 1. The purpose of this review is not to provide extensive information relating to each 3DP technology, as this has 
been covered elsewhere [13-16]. In general, each 3DP technology follow a common process for printlet production, herein described as the ' $3 \mathrm{Ds}$ of $3 \mathrm{D}$ printing' (Figure 1):

1. Design: Printlets are typically designed using CAD software to create a 3D representation of the object, often by creating a stereolithographic (.stl) file. Desired characteristics can be chosen to suit the pre-clinical or clinical requirements of the dosage form. The designed templates are then transferred to the selected 3D printer,

2. Develop: Printlets can then be developed by selecting the 3DP technology, excipients and printing parameters, which are typically based on the API characteristics and desired outcomes,

3. Dispense: The 3D printer can then be loaded with the drug-loaded feedstock. Formulations are prepared in a layer-by-layer fashion, which are then ready for 'dispensing'. This method of production varies depending on the printing platform selected.

Using this novel method of formulation production could benefit a number of clinical applications, ranging from streamlining the drug development process through to creating personalised medicines on the front-line.

\subsection{Early Phase Drug Development}

The pharmaceutical industry has faced increasing pressure in recent years to maximise the number of successful drugs reaching commercialisation [17]. It is widely understood that the rate of drug failure is high during early phase 
development [18]. It is therefore crucial for companies to rapidly identify suitable drugs at low expense as early as possible in the drug development process, ideally within pre-clinical studies or first in human $(F I H)$ clinical trials.

The ideal formulation to support early phase development would display high dose flexibility, adequate bioavailability, be easy to administer and support fast study progression at low cost [19]. However, traditional manufacturing processes often do not support this need for rapid progression, with procedures being inherently inflexible, lengthy and labour intensive. Furthermore, current formulation strategies come alongside a number of associated challenges, ranging from issues around drug solubility and stability (e.g. for liquid formulations) through to high resource investment and inadequate dose flexibility (e.g. for formulated tablets and capsules) (https://s3.amazonaws.com/cpsl-

web/kc/library/reducing_the_time_to_develop_and_manufacture_formulations _for_first_oral_dose_in_humans.pdf) [20]. Adopting 3DP as an alternative formulation-manufacturing tool could potentially overcome such challenges. The main benefits and disadvantages of using conventional formulations compared to 3DP printed tablets are listed in Table 2. In general, the major motivations for using 3DP in pre-clinical and $\mathrm{FIH}$ trials can be broken down into three main categories:

\subsubsection{Dose Flexibility}

Within early phase drug development, dose flexibility is a key requirement; in $\mathrm{FIH}$ trials, it has been estimated that dosing over a 800 -fold range is required 
[17]. Favourably, 3DP is a highly flexible process, which permits easy modification of dosages suited to the study needs. Doses could be manipulated rapidly and easily by physically modifying the tablet dimensions or infill percentage [21]. Changing the physical dimensions enabled one study to create printlets covering a wide dose range $(60-300 \mathrm{mg})$ [22]. This could provide an easier, more efficient and more precise means of dose evaluation and data collection. However, one must be mindful that altering printlet geometry could affect drug release and, as such, this would need to be accounted for in the study design [9]. A route to overcoming this could be by adjusting the 'feedstock' concentration whilst maintaining printlet geometry, or by producing rapidly dispersible or chewable printlets that permit immediate release.

\subsubsection{Reduced Labour and Resource Investment}

Using 3DP as an alternative dispensing tool could alleviate conventional manufacturing concerns, which often require time- and resource-intensive processes. There are a variety of stand-alone, compact 3D printers that could be theoretically integrated into a laboratory or clinical trial setting. For example, Makerbot sells an FDM printer with dimensions of $29.5 \times 34.9 \times 38.1 \mathrm{~cm}$ at a price of $\$ 1200$ (Replicator Mini+, https://http://www.makerbot.com/replicator-mini/). In this case, the cost of purchase, as well as the size of required operation space, is substantially lower compared with traditional large-scale tableting processes.

3DP can produce printlets in a short time frame, which is an attractive concept for resource- or time-constrained settings, such as within pre-clinical formulation 
development. On demand printing could enable the production of several product iterations for testing, enabling formulators to assess factors such as excipient inclusion and compatibility. 3D printed prototypes could help to increase understanding earlier on within drug development, decreasing time-tomarket and risks of non-adoption (https://http://www.stratasysdirect.com/content/white papers/str $746315 \mathrm{sdm}$ wp transform mfg.pdf). Within $\mathrm{FIH}$ trials, producing tailored printlets immediately prior to pre-dosing could reduce the length of storage and transportation, as well as prevent the need for stability-improving measures (e.g. refrigeration or addition of preservatives). This could negate the need for long-term accelerated storage testing which typically takes four weeks for probe batches, a condition that delays trial entry [19].

\subsubsection{Unique Characteristics}

3DP can be used to create simple and complex printlets with unique characteristics. Unlike traditional manufacturing processes, an accurate spatial distribution of drug and excipients can be attained, opening up the potential for a vast array of formulation designs and geometries to be produced [9]. Customised printlets could be based on the pharmacokinetic and pharmacodynamic characteristics of the animal model or human [23]. Goyanes. et al. 3D printed small capsular devices and used PET/CT imaging to explore the intestinal behaviour of four different polymer-based devices in rats [24, 25]. This demonstrates how 3DP can be used to tailor dosage forms and understand release profiles earlier on in drug development. 
Within FIH trials, printlets could also be tailored to meet the requirements of the study design. For example, if blinding is required (a process that prevents the participant from knowing which medicine they are receiving [26]), printlets could be designed to mask the presence of the drug. In this case, a two-compartment device could be printed, comprised of a drug 'core' embedded within a larger inert polymer tablet [27, 28]. Moreover, thermal 3DP methods (such as FDM) could be exploited as a potential enabling strategy (to increase drug bioavailability [29]), by creating a solid dispersion of an API within a polymer matrix [30, 31].

\subsection{Personalised Medicines}

Since the implementation of the Precision Medicines Initiative in the U.S. in 2015, there has been increased emphasis on moving medical treatment away from a 'one-size-fits-all' approach towards personalisation [32]. Conventionally, tablets are mass manufactured in a few discrete strengths, often based on the dose required for a suitable effect in the majority of the population [33]. However, it is evident that one dose might not fit all; requirements can vary based on a patient's genetic profile, disease state and other factors (e.g. gender, age and weight) [34, 35]. This understanding fashioned the field of personalised medicine, which commonly involves tailoring therapies to a patient based on their individual characteristics, needs and preferences [36]. 3DP could help to accelerate the field of personalised medicine by enabling the small batch production of individualised printlets directly at the point of care. This process could benefit a number of different applications on the front-line: 


\subsubsection{Paediatric and Geriatric Populations}

In young children and the elderly, dosing requirements can be markedly different compared to adults due to differences in physical characteristics and pharmacokinetics [37]. This can be particularly problematic for those medicines that are formulated as a single discrete strength or formulation type. It has become common practice for patients or carers to crush or split tablets to achieve the target dose. However such practices pose the risks of dose variation [38, 39] and dose-dumping for enteric coated tablets [40, 41]. Moreover, in the clinic, tailored formulations could be prepared via specials manufacture, however this is often attributed with high cost and delays to administration.

Printing pharmaceuticals is well suited to overcoming such challenges. Instead, clinicians or pharmacists could design a personalised dosage form containing a specific dosage and/or drug for each patient, improving treatment efficacy whilst reducing the risk of adverse effects [33]. Furthermore, to improve medication adherence and understanding, patients could be empowered to design their own printlet from a 'menu', choosing their desired formulation type and geometric factors [42]. This concept was demonstrated by Goyanes et al. [43], whereby patient acceptability of a variety of 3D printed tablet shapes, sizes and colours was evaluated. Other patient-friendly formulations, such as fastdissolving tablets [44-47] and oro-dispersible films [48] have been produced using a range of 3DP technologies. 


\subsubsection{Medicines with Complex Dosage Regimes}

Printing technologies could enable personalisation of medicines with complex dosage regimes, such as with narrow therapeutic index (TI) drugs [33, 49]. Narrow TI medicines are those that have a small difference between the therapeutic and toxic dose, whereby inappropriate dosing could lead to ineffective treatment outcomes or adverse effects. Instead of manipulating conventional fixed strength formulations, 3DP could create a printlet containing an exact dosage of drug, simplifying administration and reducing the risk of dose variation and medication errors. This has been achieved using FDM to print theophylline, a narrow TI drug used to treat asthma [28]. 3DP could also be used to simplify drug administration for medicines that have rapid dose changes on initiation or reducing regimes, such as with prednisolone [50] and budesonide $[10,28]$.

With an aging population, polypharmacy (the concurrent use of more than five medicines [51]) is an increasing consideration that can cause medication errors and non-adherence [52]. Due to the capability for accurate spatial distribution of materials, 3DP can be used to produce polypills by combining multiple actives and/or dosages into a single formulation [6, 7]. For example, a five-drug cardiac polypill was successfully 3D printed containing aspirin, hydrochlorothiazide, atenolol, ramipril and pravastatin [8]. However, it must be considered that by combining more than one medicine into the same tablet could result in a large tablet size, unfavourable for patients with dysphagia.

Encouragingly, by selecting an appropriate polymer, printlets could also be developed to have defined drug release profiles (e.g. by using different rate- 
controlling polymers [53-56]. In 2017, Goyanes. et al. [55] demonstrated that delayed release tablets could instead be produced by incorporating the drug within an enteric polymer, negating the need for an outer enteric shell.

\subsubsection{Rapid Administration and Improved Medicines Access}

3DP could be used across a number of healthcare services, ranging from primary and secondary care (e.g. community pharmacies or specialist clinics) through to tertiary care (e.g. on hospital wards). On demand dispensing in these settings could improve medicines access, reduce medicines wastage and accelerate discharge times. One-off doses could even be rapidly produced in time- or resource-constrained settings, by integrating 3D printers into disaster areas, accident \& emergency departments, first response units and military operations [57].

3DP could easily be integrated with other technological advancements of our generation, such as smart health monitors, applications and cloud-based computing. In the $21^{\text {st }}$ century, it is now feasible for patients to monitor their own vital signs (such as heart rate and blood pressure) using freely accessible applications on their smart phone devices [58]. In the future, the clinician could access these real-time data within the existing internet infrastructure, enabling easy review and modification of treatments or dosages. As 3D printers can be remotely controlled, the physician or pharmacist could design a printlet and send a prescription to a location with a 3D printer to be dispensed [13]. It could also be possible for experienced patients to own their own 3D printers for medicine dispensing, facilitating autonomy in the treatment pathway. 


\subsection{Integration of 3D printing into Clinical Pharmacy Practice}

The numerous benefits that 3DP could provide across the drug development timeline and within clinical practice are evident. However, it will come as no surprise that its integration will come alongside its own challenges [59]. The unique features of the 3DP process, combined with the relative lack of clinical history and experience compared to more established oral dosage forms and manufacturing tools, pose a number of challenges. Most notably, these relate to the matter of regulation and safety, with a number of questions still remaining unanswered. How can quality control of 3D printed dosage forms be ensured? What process controls and acceptance methods will be required? And, how can on-demand 3DP of pharmaceuticals be realised in practice?

It is likely that the short-term opportunities lie within early phase drug development, whereby 3DP integration is likely to be attainable under current regulatory pathways. For example, many clinical trial sites already have functionality for immediate preparation on site and have established manufacturing licenses and quality release protocols (https://mhrainspectorate.blog.gov.uk/2016/05/20/manufacture-of-

investigational-medicinal-products-frequently-asked-questions/). A proposed pathway could involve the printer 'feedstock' being manufactured in-house or at an external manufacturing facility and then supplied to the clinical trial site for dispensing. However, it is worth considering that many of the current 3DP platforms are not amenable for scale up, which could impact the translation of 
formulations from early phase development to later phases (i.e. Phase II/III trials).

For clinical scenarios, however, the road to integration may be more complex. Most notably, it remains undecided whether 3DP will constitute as extemporaneous preparation or a manufacturing process. Extemporaneous preparation involves clinical staff (such as a dispenser or pharmacist) mixing together one or more ingredients in response to an individual prescription [60]. For the preparation of personalised medicines, 3DP could also be viewed as an extemporaneous process: clinical staff would receive an individual order, insert a pre-prepared drug-loaded cartridge or prepare the feedstock on site, and then press 'print' for dispensing.

However, it is likely that, as 3DP is producing a formulation aesthetically similar to conventional tablets and capsules, additional testing may be required to ensure safety for human dosing. For example, printlets may require conventional tests such as content uniformity, disintegration and other characterisation procedures (e.g. tablet friability and hardness). It is likely that these requirements will vary between the different 3DP processes. The widely accepted criteria of tablets having to demonstrate $<1 \%$ weight loss in friability tests would likely be too stringent for binder jet printing, which commonly demonstrate poor mechanical strength $[61,62]$. As such, traditional quality assessment methods proposed by the FDA and pharmacopoeias may need to be revised to support 3D printed formulations. 
Moreover, undertaking such tests (especially those that are destructive, expensive or require highly skilled operators) within a clinical setting would be impractical. A proposed way to overcome such challenges could be by performing quality control checks on the drug-loaded feedstock (i.e. the initial ingredients, such as powder or drug-loaded filaments). Alternatively, novel methods of non-invasive tablet characterisation methods may be required to permit real time batch release, with the location of use and 3D printer type in mind. One method could involve process analytical technologies (PAT), such as spectroscopic tools including near infrared or raman spectroscopy, which have been used to monitor critical quality attributes such as drug content [63, 64], hardness and disintegration time [65].

In December 2017, the FDA released guidance titled 'Technical Considerations for Additive Manufactured Medical Devices', which provides an initial regulatory insight on the requirements of 3DP for medical applications [66]. For both small and large-scale manufacture of oral dosage forms, it is clear that all aspects of the printing process will require thorough evaluation to ensure product quality (e.g. hardware, software, raw materials and supplier, operator training and quality controls). Notably, there are several 3DP platforms, each with their own unique requirements, ranging from modes of operation, material inclusion and post-processing techniques. For the selected 3DP process, it will be important to clearly identify each variable that could impact final dosage form performance. 
For example, if using 3DP on demand within a hospital scenario, dosage forms may need to be designed based on clinical assessments. As such, a clear identification of clinically relevant design parameters (such as geometry and infill percentage) and acceptable parameter ranges (e.g. minimum/maximum values) will be required [66]. Importantly, fabricating different printlet geometries could change drug release, potentially increasing research costs and efforts to understand the impact of these parameters. Furthermore, different 3DP technologies have different considerations that could be important to dosage form design. For example, FDM and SLS use heat and a laser, respectively, as part of the 3DP process, both posing the risk of premature API degradation [11]. Moreover, SLA is known to induce toxicity due to the use of non-pharmaceutical grade excipients [67]. Further to this, current commercial 3D printers have not been designed for good manufacturing practice (GMP) use; that is, a manufacturing platform that has been validated to ensure that the final drug product is safe for human consumption

(https://http://www.fda.gov/Drugs/DevelopmentApprovalProcess/Manufacturin g/ucm169105.htm). Such requirements dictate that the printer parts in contact with the formulation must not leach materials and must be easily cleanable [68]. As such, further development will be required to ensure that these platforms are fit-for-purpose.

Indeed, it is clear that the 'ideal 3D printer' for personalised medicine has not yet been developed. Predominantly, this ideal printer would be affordable, produce versatile dosage forms with acceptable safety, quality and stability, 
have low consumption, and be user-friendly for non-experts of 3DP (Figure 2). Critically, to enable this ideal technology to be developed and integrated into clinical practice, a multidisciplinary team of 3D printer manufacturers, formulation scientists, excipient suppliers and pharmaceutical regulators are required to come together. Only via an agreed consensus would these changes be able to be made, hurdles to be faced and integration to be attainable.

Whilst integration of 3DP into clinical practice may be in its infancy, progress is being made every day. Conversations between our research group, the pharmaceutical industry and regulators have already begun to further understand the requirements of each stakeholder. Furthermore, in the U.S., a number of initiatives have been implemented, such as the FDA's Emerging Technology Team (EET), which aim to encourage the application of technological innovation to product design and manufacturing and have since recognised 3DP as a potential manufacturing platform (https://http://www.fda.gov/AboutFDA/CentersOffices/OfficeofMedicalProductsa ndTobacco/CDER/ucm523228.htm). The Center for Drug Evaluation and Research Office of Pharmaceutical Quality has also established a manufacturing science program to investigate the use of innovative technologies in manufacturing, including 3DP [69].These regulatory initiatives will likely aid in progressing 3DP from a theoretical prospect to a realistic and revolutionary manufacturing tool to support the pharmaceutical industry. 


\subsection{Concluding Remarks}

The power of 3DP in pharmaceuticals is evident. This technology could revolutionise formulation production, to move away from mass manufacture to producing highly flexible and personalised dosage forms on-demand. Tailored formulations could benefit a number of applications, extending from drug development (pre-clinical studies and FIH trials) to front-line medical care (personalised medicine). The recent FDA approval of the first 3D printed tablet $\left(\right.$ Spritam $\left.^{\circledR}\right)$ was a significant milestone in this technology's history. 3DP is expected to continue rapidly evolving over the next decade. Progress is already being made, with cutting-edge research being published everyday, detailing the new possibilities that 3DP can bring.

Despite its substantial progress, using 3DP to produce drug products still remains in its infancy. A number of regulatory requirements need to be overcome before the widespread integration of 3DP into practice. However, the numerous benefits that this technology can bring cannot be overlooked. It is critical, now more than ever, for the pharmaceutical industry to not resist change, but to instead understand and embrace the power of 3DP in pharmaceuticals.

\subsection{Acknowledgements}

The authors would like to thank Dr. Martin Rowland for his review of the manuscript and contribution of additional industrial perspectives. The authors thank the Engineering and Physical Sciences Research Council (EPSRC), UK for their financial support (EP/L01646X). 


\subsection{References}

1 Yao, R., et al. (2016) Three-dimensional printing: review of application in medicine and hepatic surgery. Cancer Biol Med 13, 443-451

2 Barnatt, C. (2013) 3D Printing: The Next Industrial Revolution. ExplainingTheFuture.com

3 Huang, W., et al. (2007) Levofloxacin implants with predefined microstructure fabricated by three-dimensional printing technique. Int. J. Pharm. 339, 33-38

4 Weigang, W., et al. (2009) A programmed release multi-drug implant fabricated by three-dimensional printing technology for bone tuberculosis therapy. Biomed Mater 4, 065005

5 Muwaffak, Z., et al. (2017) Patient-specific 3D scanned and 3D printed antimicrobial polycaprolactone wound dressings. Int. J. Pharm. 527, 161-170

6 Khaled, S.A., et al. (2015) 3D printing of tablets containing multiple drugs with defined release profiles. Int. J. Pharm. 494, 643-650

7 Goyanes, A., et al. (2015) 3D Printing of Medicines: Engineering Novel Oral Devices with Unique Design and Drug Release Characteristics. Mol Pharm $12,4077-4084$

8 Khaled, S.A., et al. (2015) 3D printing of five-in-one dose combination polypill with defined immediate and sustained release profiles. J Control Release 217, 308-314

9 Goyanes, A., et al. (2015) Effect of geometry on drug release from 3D printed tablets. Int. J. Pharm. 494, 657-663

10 Goyanes, A., et al. (2015) Fabrication of controlled-release budesonide tablets via desktop (FDM) 3D printing. Int. J. Pharm. 496, 414-420 
11 Goyanes, A., et al. (2015) 3D printing of modified-release aminosalicylate (4-ASA and 5-ASA) tablets. Eur J Pharm Biopharm 89, 157-162

12 ASTM (2016) Standard Guidelines for Design for Additive Manufacturing. In Section 3: Terminology

13 Alhnan, M.A., et al. (2016) Emergence of 3D Printed Dosage Forms: Opportunities and Challenges. Pharm Res 33, 1817-1832

14 Goole, J. and Amighi, K. (2016) 3D printing in pharmaceutics: A new tool for designing customized drug delivery systems. Int. J. Pharm. 499, 376-394

15 Stansbury, J.W. and Idacavage, M.J. (2016) 3D printing with polymers: Challenges among expanding options and opportunities. Dental Materials 32 , $54-64$

16 Prasad, L.K. and Smyth, H. (2016) 3D Printing technologies for drug delivery: a review. Drug Dev Ind Pharm 42, 1019-1031

$17 \mathrm{Ku}$, M.S. and Dulin, W. (2012) A biopharmaceutical classification-based Right-First-Time formulation approach to reduce human pharmacokinetic variability and project cycle time from First-In-Human to clinical Proof-OfConcept. Pharm Dev Technol 17, 285-302

18 Hay, M., et al. (2014) Clinical development success rates for investigational drugs. Nat Biotech 32, 40-51

19 Kwong, E. (2017) Oral Formulation Roadmap from Early Drug Discovery To Development. John Wiley \& Sons, Inc 20 Kuentz, M., et al. (2016) Methodology of oral formulation selection in the pharmaceutical industry. European Journal of Pharmaceutical Sciences 87, 136-163 
21 Goyanes, A., et al. (2014) Fused-filament 3D printing (3DP) for fabrication of tablets. Int. J. Pharm. 476, 88-92

22 Pietrzak, K., et al. (2015) A flexible-dose dispenser for immediate and extended release 3D printed tablets. Eur. J. Pharm. Biopharm. 96, 380-387 23 Genina, N., et al. (2017) Anti-tuberculosis drug combination for controlled oral delivery using 3D printed compartmental dosage forms: From drug product design to in vivo testing. J Control Release 268, 40-48

24 Goyanes, A., et al. (2018) PET/CT imaging of 3D printed devices in the gastrointestinal tract of rodents. Int. J. Pharm. 536, 158-164

25 Hatton, G.B., et al. (2015) Animal Farm: Considerations in Animal Gastrointestinal Physiology and Relevance to Drug Delivery in Humans. $J$ Pharm Sci 104, 2747-2776

26 Page, S.J. and Persch, A.C. (2013) Recruitment, Retention, and Blinding in Clinical Trials. The American Journal of Occupational Therapy 67, 154-161 $27 \mathrm{Li}, \mathrm{Q}$., et al. (2017) Preparation and investigation of controlled-release glipizide novel oral device with three-dimensional printing. Int. J. Pharm. 525, $5-11$

28 Okwuosa, T.C., et al. (2017) Fabricating a Shell-Core Delayed Release Tablet Using Dual FDM 3D Printing for Patient-Centred Therapy. Pharm Res $34,427-437$

29 Ayad, M.H. (2015) Rational formulation strategy from drug discovery profiling to human proof of concept. Drug Deliv 22, 877-884 30 Zhang, J., et al. (2017) Coupling 3D printing with hot-melt extrusion to produce controlled-release tablets. Int. J. Pharm. 519, 186-197 
31 Fina, F., et al. (2017) Selective laser sintering (SLS) 3D printing of medicines. Int. J. Pharm. 529, 285-293

32 Collins, F.S. and Varmus, H. (2015) A New Initiative on Precision Medicine. N Engl J Med 372, 793-795

33 Alomari, M., et al. (2015) Personalised dosing: Printing a dose of one's own medicine. Int. J. Pharm. 494, 568-577

34 Hamburg , M.A. and Collins , F.S. (2010) The Path to Personalized Medicine. N Engl J Med 363, 301-304

35 Florence, A.T. and Lee, V.H.L. (2011) Personalised medicines: More tailored drugs, more tailored delivery. Int. J. Pharm. 415, 29-33

36 Srivastava, S.C. (2012) Paving the Way to Personalized Medicine: Production of Some Promising Theragnostic Radionuclides at Brookhaven National Laboratory. Semin Nucl Med 42, 151-163

37 Breitkreutz, J. and Boos, J. (2007) Paediatric and geriatric drug delivery. Expert Opin Drug Deliv 4, 37-45

38 Habib, W.A., et al. (2014) Accuracy of tablet splitting: Comparison study between hand splitting and tablet cutter. Saudi Pharm J 22, 454-459

39 Madathilethu, J., et al. (2018) Content uniformity of quartered hydrocortisone tablets in comparison with mini-tablets for paediatric dosing. BMJ Paediatrics Open 2

40 Hill, S., et al. (2009) Analysis of Drug Content and Weight Uniformity for Half-Tablets of 6 Commonly Split Medications. J Manag Care Pharm 15, 253261

41 Elliott, I., et al. (2014) The practice and clinical implications of tablet splitting in international health. Trop Med Int Health 19, 754-760 
42 Scoutaris, N., et al. (2018) 3D printed "Starmix" drug loaded dosage forms for paediatric applications. Pharm Res 35, 34

43 Goyanes, A., et al. (2017) Patient acceptability of 3D printed medicines. Int. J. Pharm. 530, 71-78

44 Yu, D.G., et al. (2009) Novel oral fast-disintegrating drug delivery devices with predefined inner structure fabricated by Three-Dimensional Printing. $J$ Pharm Pharmacol 61, 323-329

45 Sadia, M., et al. (2018) Channelled tablets: An innovative approach to accelerating drug release from 3D printed tablets. J Control Release 269, $355-363$

46 Solanki, N.G., et al. (2018) Formulation of 3D Printed Tablet for Rapid Drug Release by Fused Deposition Modeling: Screening Polymers for Drug Release, Drug-Polymer Miscibility and Printability. J Pharm Sci 107, 390-401 47 Fina, F., et al. (2018) Fabricating 3D printed orally disintegrating tablets using selective laser sintering. Int. J. Pharm. In Press

48 Jamróz, W., et al. (2017) 3D printed orodispersible films with Aripiprazole. Int. J. Pharm. 533, 413-420

49 Vuddanda, P.R., et al. (2018) Personalisation of warfarin therapy using thermal ink-jet printing. Eur J Pharm Sci

50 Skowyra, J., et al. (2015) Fabrication of extended-release patient-tailored prednisolone tablets via fused deposition modelling (FDM) 3D printing. Eur $J$ Pharm Sci 68, 11-17

51 Masnoon, N., et al. (2017) What is polypharmacy? A systematic review of definitions. BMC Geriatrics 17, 230 
52 Maher, R.L., et al. (2014) Clinical consequences of polypharmacy in elderly. Expert Opin Drug Saf 13, 57-65

53 Gioumouxouzis, C.I., et al. (2017) 3D printed oral solid dosage forms containing hydrochlorothiazide for controlled drug delivery. J Drug Deliv Sci Technol 40, 164-171

54 Maroni, A., et al. (2017) 3D printed multi-compartment capsular devices for two-pulse oral drug delivery. J Control Release 268, 10-18

55 Goyanes, A., et al. (2017) Development of modified release 3D printed tablets (printlets) with pharmaceutical excipients using additive manufacturing. Int. J. Pharm. 527, 21-30

56 Melocchi, A., et al. (2015) 3D printing by fused deposition modeling (FDM) of a swellable/erodible capsular device for oral pulsatile release of drugs. $J$ Drug Deliv Sci Techn 30, Part B, 360-367

57 Norman, J., et al. (2017) A new chapter in pharmaceutical manufacturing: 3D-printed drug products. Adv Drug Deliv Rev 108, 39-50

58 Zanaboni, P. and Wootton, R. (2012) Adoption of telemedicine: from pilot stage to routine delivery. BMC Med Inform Decis Mak 12, 1-1

59 Kaae, S., et al. (2018) Unintended consequences for patients of future personalized pharmacoprinting. Int J Clin Pharm

60 McCague, P.M., J; Donnelly, R. (2012) What are your views on specials and extemporaneous medicines preparation? Pharmaceutical Journal

61 FDA (2017) Tablet Friability General Chapter Guidance for Industry Annex 9(R1). (U.S. Department of Health and Human Services, ed)

$62 \mathrm{Yu}$, D.G., et al. (2008) Three-Dimensional Printing in Pharmaceutics: Promises and Problems. J Pharm Sci 97, 3666-3690 
63 Meza, C.P., et al. (2006) Quantitation of drug content in a low dosage formulation by transmission near infrared spectroscopy. AAPS PharmSciTech 7, E206-E214

64 Wartewig, S. and Neubert, R.H.H. (2005) Pharmaceutical applications of Mid-IR and Raman spectroscopy. Adv Drug Deliv Rev 57, 1144-1170 65 Blanco, M., et al. (2006) A process analytical technology approach based on near infrared spectroscopy: Tablet hardness, content uniformity, and dissolution test measurements of intact tablets. J Pharm Sci 95, 2137-2144 66 FDA (2017) Technical Considerations for Additive Manufactured Medical Devices. (U.S. Department of Health and Human Services, ed)

67 Arcaute, K.M., B; Wicker, R. (2006) Stereolithography of ThreeDimensional Bioactive Poly(Ethylene Glycol) Constructs with Encapsulated Cells. Ann Biomed Eng 34, 1429-1441

68 ICH (2000) Good Manufacturing Practice Guide for Active Pharmaceutical Ingredients. (ICH Harmonised Tripartite Guideline, ed)

69 Markarian, J. (2016) FDA and the Emerging Technology of 3D Printing. Pharm Tech 40

70 Wu, B.M., et al. (1996) Solid free-form fabrication of drug delivery devices. J Control Release 40, 77-87

71 Wang, J., et al. (2016) Stereolithographic (SLA) 3D printing of oral modified-release dosage forms. Int. J. Pharm. 503, 207-212

72 Katstra, W.E., et al. (2000) Oral dosage forms fabricated by Three Dimensional Printing ${ }^{\mathrm{TM}}$. J Control Release 66, 1-9

73 Jacob, J., et al. (2014) Rapid Disperse Dosage Form Containing Levetiracetam. Google Patents 
74 Goyanes, A., et al. (2016) Fused-filament 3D printing of drug products: Microstructure analysis and drug release characteristics of PVA-based caplets. Int. J. Pharm. 514, 290-295

75 Khaled, S.A., et al. (2014) Desktop 3D printing of controlled release pharmaceutical bilayer tablets. Int. J. Pharm. 461, 105-111

76 Salmoria, G.V., et al. (2013) The effects of laser energy density and particle size in the selective laser sintering of polycaprolactone/progesterone specimens: morphology and drug release. Int J Adv Manuf Technol 66, 11131118

77 Wang, C.C., et al. (2006) Development of near zero-order release dosage forms using three-dimensional printing (3-DP) technology. Drug Dev Ind Pharm 32, 367-376

78 Martinez, P.R., et al. (2017) Fabrication of drug-loaded hydrogels with stereolithographic 3D printing. Int. J. Pharm. 532, 313-317

79 Goyanes, A., et al. (2016) 3D scanning and 3D printing as innovative technologies for fabricating personalized topical drug delivery systems. $J$ Control Release 234, 41-48

\section{Glossary}

API: Active pharmaceutical ingredient; used to describe the pharmaceutically active component of the dosage form

Binder jet printing: a powder bed 3D printing method that uses a binder liquid to agglomerate powder particles to create a solid object 
CAD software: Computer aided design software; used to digitally design the 3D printed object

FDM: Fused Deposition Modeling; a thermal extrusion 3D printing method FIH trials: first in human clinical trials; represents the first administration of a drug in humans to evaluate initial efficacy, toxicology and pharmacokinetics. Printlets: A word that we have coined to describe 3D printed oral dosage forms

Semi-solid extrusion: a 3D printing method that is based on the extrusion of semi-solid materials (such as gels or pastes) that solidify to create a solid object.

SLA: Stereolithography; a 3D printing method that uses high energy light to photopolymerise a liquid resin to create solid parts SLS: Selective laser sintering; a powder bed 3D printing method that uses a laser to sinter powder particles together to create a solid object 
Tables (1-2) in order of citation:

Table 1

\begin{tabular}{|c|c|c|c|c|c|}
\hline $\begin{array}{l}\text { 3D Printing } \\
\text { Technology }\end{array}$ & Formulation & Study Aim & API & Excipients & Reference \\
\hline \multirow{4}{*}{$\begin{array}{l}\text { Binder Jet } \\
\text { Printing }\end{array}$} & Tabular device & $\begin{array}{c}\text { Fabrication of novel drug } \\
\text { delivery devices }\end{array}$ & $\begin{array}{l}\text { Methylene blue and } \\
\text { alizarin yellow (dyes) }\end{array}$ & PCL and PEO & {$[70]$} \\
\hline & Tablets & $\begin{array}{c}\text { Fabrication of fast } \\
\text { dissolving drug delivery } \\
\text { device }\end{array}$ & $\begin{array}{c}\text { Paracetamol and } \\
\text { alizarin yellow (dye) }\end{array}$ & $\begin{array}{c}\text { Colloidal } \mathrm{SiO}_{2} \text {, mannitol, PVP } \\
\text { K30 and lactose }\end{array}$ & {$[44]$} \\
\hline & $\begin{array}{l}\text { Cubic tabular } \\
\text { devices }\end{array}$ & $\begin{array}{c}\text { Development of near } \\
\text { zero-order release } \\
\text { dosage forms }\end{array}$ & Pseudoephedrine & Kollidon SR, HPMC & [71] \\
\hline & Tablets & $\begin{array}{l}\text { Fabrication of erosion- } \\
\text { mechanism delayed } \\
\text { release tablets }\end{array}$ & $\begin{array}{l}\text { Chlorphenamine } \\
\text { maleate and } \\
\text { fluoroscein }\end{array}$ & $\begin{array}{l}\text { Avicel PH301, Eudragit E-100, } \\
\text { RLPO in ethanol or acetone, or } \\
\text { PVP and Tween } 20 \text { in } \\
\text { deionised water }\end{array}$ & [72] \\
\hline
\end{tabular}




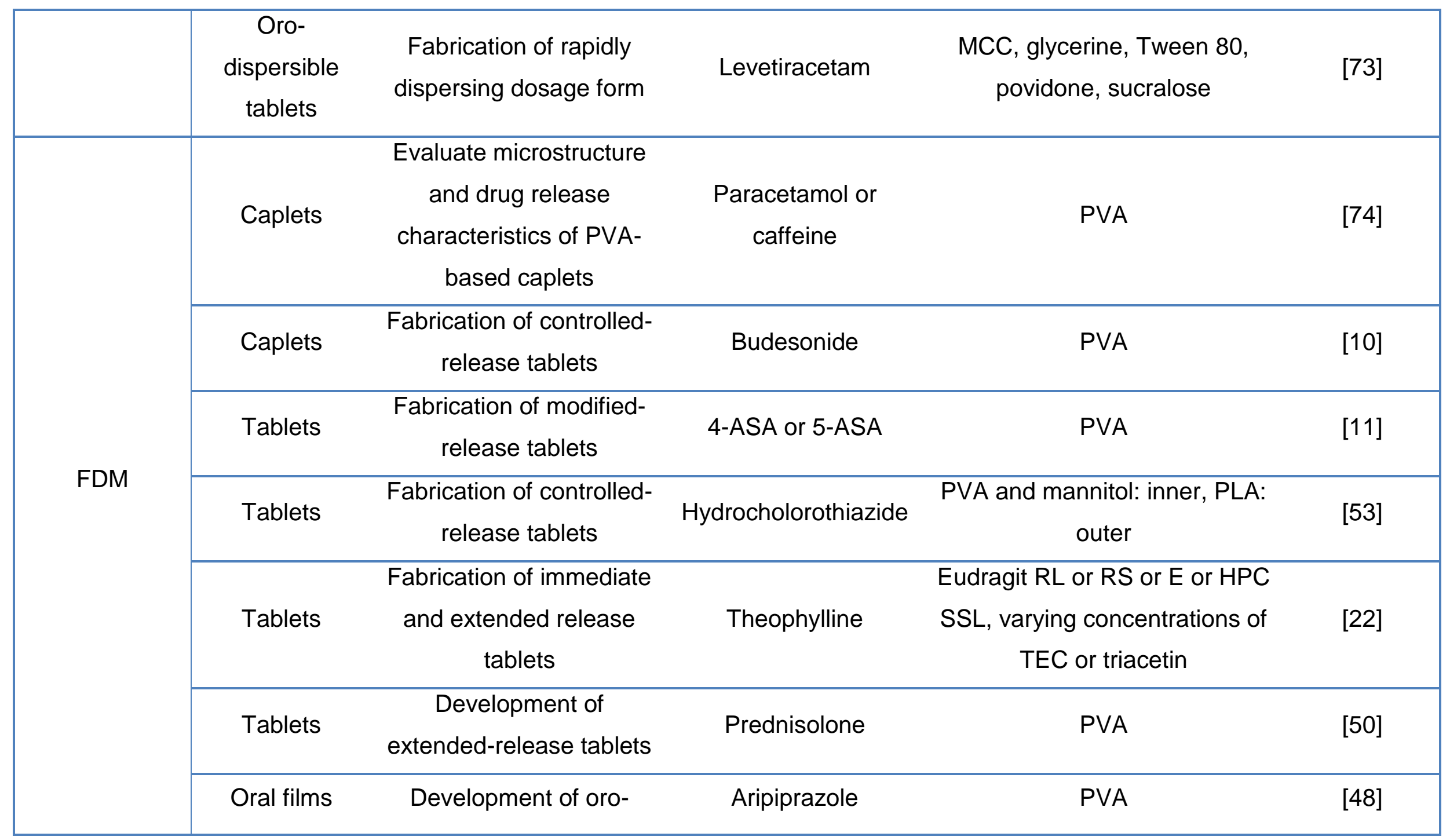




\begin{tabular}{|c|c|c|c|c|c|}
\hline & & dispersible films (ODFs) & & & \\
\hline \multirow{3}{*}{$\begin{array}{l}\text { Semi-solid } \\
\text { Extrusion }\end{array}$} & $\begin{array}{l}\text { Bi-layered } \\
\text { tablets } \\
\text { (polypill) }\end{array}$ & $\begin{array}{l}\text { Fabrication of bi-layered } \\
\text { tablets for respiratory } \\
\text { tract infections }\end{array}$ & Guafenisin & $\begin{array}{l}\text { PAA, MCC and sodium starch } \\
\text { glycolate }\end{array}$ & [75] \\
\hline & $\begin{array}{l}\text { Multi-active } \\
\text { tablets } \\
\text { (polypill) }\end{array}$ & $\begin{array}{l}\text { Fabrication of a complex } \\
\text { tablet displaying } \\
\text { sustained release of } \\
\text { nifedipine and glipizide } \\
\text { and osmotic pump for } \\
\text { captopril }\end{array}$ & $\begin{array}{l}\text { Nifedipine, glipizide } \\
\text { and captopril }\end{array}$ & HPMC & [6] \\
\hline & $\begin{array}{l}\text { Multi-active } \\
\text { tablets } \\
\text { (polypill) }\end{array}$ & $\begin{array}{l}\text { Fabrication of a complex } \\
\text { tablet comprised of five } \\
\text { different drugs for } \\
\text { cardiovascular disease }\end{array}$ & $\begin{array}{l}\text { Hydrochlorothiazide, } \\
\text { aspirin, pravastatin, } \\
\text { atenolol and ramipril }\end{array}$ & $\begin{array}{c}\text { PEG600, D-mannitol, cellulose } \\
\text { acetate }\end{array}$ & [8] \\
\hline \multirow[b]{2}{*}{ SLS } & Tablets & $\begin{array}{l}\text { Fabrication of oral drug } \\
\text { loaded tablets using SLS }\end{array}$ & Paracetamol & $\begin{array}{l}\text { Kollicoat IR or Eudragit L, } \\
\text { candurin gold sheen }\end{array}$ & [31] \\
\hline & $\begin{array}{l}\text { Drug delivery } \\
\text { device }\end{array}$ & $\begin{array}{c}\text { Production of } \\
\text { PCL/progesterone drug } \\
\text { delivery device }\end{array}$ & Progesterone & PCL & [76] \\
\hline
\end{tabular}




\begin{tabular}{|c|c|c|c|c|c|}
\hline \multirow{3}{*}{ SLA } & Tablets & $\begin{array}{l}\text { Fabrication of modified- } \\
\text { release tablets using } \\
\text { SLA }\end{array}$ & $\begin{array}{c}\text { Paracetamol or 4- } \\
\text { ASA }\end{array}$ & $\begin{array}{c}\text { PEGDA, PEG } 300 \text { and } \\
\text { diphenyl }(2,4,6- \\
\text { timethylbenzoyl)phosphine } \\
\text { oxide }\end{array}$ & [77] \\
\hline & Hydrogels & $\begin{array}{l}\text { Fabrication of drug- } \\
\text { loaded hydrogels }\end{array}$ & Ibuprofen & $\begin{array}{c}\text { PEGDA, PEG 300, } \\
\text { diphenyl(2,4,6- } \\
\text { timethylbenzoyl)phosphine } \\
\text { oxide or riboflavin and } \\
\text { triethanolamine }\end{array}$ & [78] \\
\hline & Facial Mask & $\begin{array}{c}\text { Fabrication of } \\
\text { personalised anti-acne } \\
\text { facial masks }\end{array}$ & Salicylic acid & $\begin{array}{c}\text { PEGDA, PEG 300, } \\
\text { diphenyl }(2,4,6- \\
\text { timethylbenzoyl)phosphine } \\
\text { oxide }\end{array}$ & [79] \\
\hline
\end{tabular}




\begin{tabular}{|c|c|c|c|c|}
\hline & Formulation & Advantages & Disadvantages & Reference \\
\hline \multirow{2}{*}{ 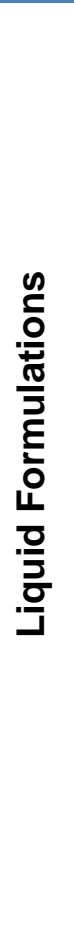 } & $\begin{array}{l}\text { Ready-to-use } \\
\text { solutions and } \\
\text { suspensions }\end{array}$ & $\begin{array}{l}\text { - High dose flexibility } \\
\text { - } \quad \text { Can be used for pre-clinical and clinical studies } \\
\text { - } \quad \text { Cheap and easy to manufacture } \\
\text { - Well established preparative techniques } \\
\text { - Suitable for patients with dysphagia } \\
\text { - }\end{array}$ & $\begin{array}{l}\text { - Drug stability may be an issue } \\
\text { - Microbial stability may be an issue } \\
\text { - May not be suitable for poorly soluble } \\
\text { compounds } \\
\text { May not be suitable for bitter APIs that require } \\
\text { taste masking }\end{array}$ & [19] \\
\hline & Drug-in-bottle & $\begin{array}{l}\text { - High dose flexibility } \\
\text { - Possible for on-site reconstitution } \\
\text { - Well established preparative techniques } \\
\text { - } \text { Could be used for both preclinical and clinical } \\
\text { - studies } \\
\text { - Suitable for patients with dysphagia } \\
\text { - } \text { - Ontomated equipment available for production }\end{array}$ & $\begin{array}{l}\text { - Excipients may be needed for re- } \\
\text { suspendibility } \\
\text { - May not be suitable for bitter APIs that } \\
\text { require taste masking } \\
\text { - May not be suitable for poorly soluble } \\
\text { compounds } \\
\text { Clinical staff require training for extemporaneous } \\
\text { preparation }\end{array}$ & [20] \\
\hline 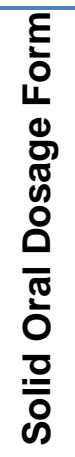 & Drug-in-capsule & $\begin{array}{l}\text { - } \text { Taste masking possible } \\
\text { - Blinding can be achieved } \\
\text { - Well established preparative techniques } \\
\text { - } \quad \text { Automated equipment available for production } \\
\text { - Accelerate FIH trial entry }\end{array}$ & $\begin{array}{l}\text { - Low dose flexibility } \\
\text { - Requires adequate flow characteristics } \\
\text { - May not be suitable for poorly soluble, low } \\
\text { potency or low density compounds } \\
\text { - Laborious and time-consuming if dispensing } \\
\text { by hand }\end{array}$ & [20] \\
\hline
\end{tabular}


Table 2

\begin{tabular}{|c|c|c|c|}
\hline $\begin{array}{l}\text { Formulated tablets } \\
\text { and capsules }\end{array}$ & $\begin{array}{l}\text { - } \text { Can be used for commercial formulation } \\
\text { development } \\
\text { - } \text { Automated equipment available for production } \\
\text { - } \text { Well established preparative techniques } \\
\text { - Blinding and taste-masking possible if using } \\
\text { - } \text { capsules or by coating tablets } \\
\text { Amenable for scale-up }\end{array}$ & $\begin{array}{l}\text { - } \text { Low dose flexibility } \\
\text { - } \text { Higher resource input (e.g. lengthier } \\
\text { - Often unsuitable for preclinical studies } \\
\text { - } \quad \text { Excipient compatibility studies may be needed } \\
\text { Can delay start to FIH trial entry }\end{array}$ & [19] \\
\hline $\begin{array}{l}\text { 3DP Tablets } \\
\text { (Printlets) }\end{array}$ & $\begin{array}{l}\text { - } \text { High dose flexibility } \\
\text { - } \text { - Chitable for formulation development } \\
\text { - Suitable for paediatrics and patients with } \\
\text { - } \text { dysphagia (e.g. older patients) } \\
\text { - } \text { Possibility for on-site preparation } \\
\text { - } \text { Automated equipment available for production } \\
\text { - Only short term stability data required } \\
\text { - Taste masking and blinding possible } \\
\text { - Thermal methods could serve as an enabling } \\
\text { strategy }\end{array}$ & $\begin{array}{l}\text { - May be unsuitable for thermally labile drugs } \\
\text { (FDM) } \\
\text { - Regulatory requirements require addressing } \\
\text { - } \quad \text { Technical challenges need to be overcome } \\
\text { - } \quad \text { Current 3D printers are not amenable for } \\
\text { scale up, except in the case of binder jetting }\end{array}$ & [13] \\
\hline
\end{tabular}


Figure and Table Legends (in order of citation):

Figure 1. The 3 Ds of 3D Printing: Basic principle of 3D printing oral dosage forms

Table 1: Examples of oral dosage forms produced using different 3D printing technologies

Table 2: The advantages and disadvantages of conventional and 3D printing processes to produce medicines within $\mathrm{FIH}$ trials

Figure 2. The 'ideal 3D printer' for production of personalised medicines 